\title{
EDITORIAL
}

\section{MEDICAL SERVICES IN THE FIELD-A LOOK AHEAD}

The strategy and tactical doctrine of the 1970's will create many problems for field medical units if they are to continue to provide their usual high standard of care. To stimulate thought on these problems an assessment of possible tactical deployments is necessary. The Strategic Reserve must be quick in reaction, mobile and highly flexible; this will necessitate air transportation not only to the scene of operations but also on the battlefield. In mechanised warfare in the late 1970's tanks and infantry may well conduct mobile defensive operations in open country, in depth, complemented by an air-mobile infantry as guerillas in close country. Ground-based lines of communication would then to a large extent be abandoned. In general war in the early 1970's tactical deployment could change frequently and drastically. The wide dispersion of battle groups, coupled with the concept of mobile operations, will cause major disruption to a normal ground-based logistic supply system. These units may be inaccessible, except by air, for varying lengths of time.

Under these circumstances a fixed surface system of casualty evacuation would be inflexible and inadequate. Because of the increased dependence upon air evacuation the allocation to units of permanent helicopter ambulances would be ideal. Unfortunately, this is not likely to occur for some very considerable time and use must continue to be made of returning empty helicopters. Air evacuation itself will be a practicable possibility only if there is at least air parity. The problem remains, therefore, of producing adequate treatment for troops divorced from base facilities for variable lengths of time.

With highly mobile and dispersed troops there will be a delay in the evacuation of casualties from the Forward Edge of the Battle Area (FEBA). The effects of this can be mitigated to a certain extent by a very high standard of first aid being practised by all ranks and great emphasis being given to this subject in unit training. To facilitate casualty collection Field Ambulance sections, commanded perhaps by senior noncommissioned officers, may well have to be deployed in 'mopping up' operations, sections commanded by medical officers being strategically placed to provide care in transit.

The present policy of where and when to perform surgery may also require reappraisal. This could well have to be performed at Advanced Dressing Station (ADS) level when this unit would have to function as an Advanced Surgical Centre. To provide good post-operative nursing at this level, elements of the Field Hospital would have to be deployed with the Field Surgical Team. This element would require to be of a reasonable size and to a large extent self-contained if the ADS is not to be immobilized.

Resupply of medical stores will present its own problems and will have to be integrated with the logistic groups deployed to support the force as a whole. An analysis of holdings will be essential if units are to remain viable in spite of uncertain lines of communication. Disposable items, for example, may not be as useful as they would seem to be under these circumstances.

To meet the requirements of the 1970 's all field medical units must be highly mobile, flexible and adaptable. The eventual outcome may be the evolution of two basic casualty handling units, a forward unit developed from the present Field Ámbulance, and a rear 
unit, a Field Hospital, based on the present Casualty Clearing Station. These might well be composed of blocks built around an administrative nucleus, the actual number of blocks depending on the tactical situation.

\section{"Acknowledgements" by Authors}

There would appear to be some uncertainty as to whom contributors to the Journal should properly make acknowledgements. The following ruling has been obtained from the Ministry of Defence.

"There is no objection to acknowledgements being made in papers submitted for publication, if professional assistance with regard to medical matters has been obtained in compiling the paper.

Mention should not be made of individuals who have not provided such professional assistance.

Acknowledgements should not be made of assistance from the Ministry of Defence, or of clearance for publication by the Ministry of Defence.

Acknowledgements should not be made to such organisations as CDEE or MRE without first clearing with such organisations."

\section{Author's correction}

Volume 114, Issue No. 1, 1968

Page 24 under "The Radiological and Bacteriological Assessment of Tuberculous Lung Lesions Remaining after Long Term Alternate-Day Dual Drug Chemotherapy ", paragraph one, line five, for "The findings on long term follow-up of these patients were later reported by Large and Dimond (1964)", read "The findings on long term follow-up of Gurkha patients treated on this chemotherapeutic regime alone, before facilities for resection were available to them were later reported by Large and Dimond (1964)". 